\title{
A Clinical Study of Childhood Blindness
}

\author{
Dr. D. Bhima Sankar Babu M.S ${ }^{1}$, Dr. M.Vijayaleela M.S ${ }^{2}$ \\ ${ }^{1}$ Associate Professor Of Ophthalmology Sarojini Devi Eye Hospital \\ ${ }^{2}$ Associate Professor Of Ophthalmology Nizamabad
}

\section{Abstract:}

- Children aged 0-15 years, and with presenting visual acuity in the better eye of less than 6/60 were included in the study

- Individual aged less than 16 years old.

- The visual acuity was tested considering the age of the child.

- Landolt's broken-C test,Snellen chart was used for children who could follow the test and for children unable to follow the test types, counting fingers was considered.

- In infants visual acuity was tested by their ability to fix and follow the light.

Type Of Study: Retrospective study

Place Of Study:Sarojini Devi Eye Hospital

Aim:

1.To study the Epidemiology of childhood blindness

2. To study the etiology and incidence of treatable causes of childhood blindness

Materials And Methods

- A Retrospective hospital based study was done at Sarojinidevi Eye Hospital, Hyderabad for 2 years(20142016).

- Children aged 0-15 years with visual acuity<6/60 in the better eye were included.

- Children attending the out-patient Department of Ophthalmology,Sarojinidevi Eye Hospital were examined.

The visual acuity was tested considering the age of the child.

- Landolt's brocken-C test,snellen chart was used for children who could follow the test and for children unable to follow the test types, counting fingers was considered.

- In infants visual acuity was tested by their ability to fix and follow the light.

Inclusion criteria: Amblyopia Caused by Uncorrected Refractive Errors Globe anomalies Retinal Lesions and Congenital Cataract

Exclusion Criteria

- Children who had turned 16 before or during the duration of the study and those whose presenting vision was $>6 / 60$ in the better eye were excluded from the study.

- Parent not willing to sign informed consent.

- Period of studyFrom 2014 to2016.

\section{Introduction}

Blindness is defined as visual acuity $<3 / 60$ in the better eye with best possible refractive correction.Economic Blindness: Vision less than 6/60 is termed economic blindness Social blindness: vision 1/60to3/60 is termed social blindness.Legal blindness: vision 1/60 to PL is termed legal blindness.

causes of childhood blindness

\section{Discussion}

- Anatomical classificition

- Anomalies of the globe:

-microphthalmos

-Anophthalmos

-Phthisis bulbi

-Atrophic bulbi

Corneal leisions:

-Corneal scar

-Anterior staphyloma

-Corneal Dystrophy

- Disorders of the lens: 
-Congenitial cataract

-Coloboma of lens

-Heritable ectopia lentis

-Aphakia

Uveal Conditions:

-Coloboma Of Iris

-Aniridia

-Uveitis

Retinal Disorders:

-Retinal Dystrophies

-Retinopathy Of Prematurity

-Retinal Detachment

Optic Nerve Diseases:

-Optic Atrophy

-Hypoplasia Of Optic Disc

-Coloboma Of Disc

-Optic Disc Pit

Glaucoma:

-Buphthalmos

Others:

-Cortical Blindness

-Amblyopia

- Childhood blindness is a major and widely prevalent disorder in this part of our country. Preventable blindness forms a significant proportion of the total blindness.

- The percentage of treatable blindness in this study is $46 \%$ and this figure correlates well with the earlier studies by Dandona and Dandona(Br.J.O.2013). Amblyopia caused by uncorrected refractive errors is still a major and eminently treatable cause of blindness in children(27\%).

- The major preventable cause of childhood blindness is corneal scar due to vitamin A deficiency(11\%).

- Other causes of blindness include globe anomalies(17\%), Retinal lesions(12\%) and Congenital cataract $(8 \%)$.

- Overwhelming majority of cases of blindness have been detected in the school going age group(5-15 yrs, $91 \%$ ) followed by $1-3$ yr age group $(6 \%)$.

Obsrvations

Anatomical Cause Of Blindneess

$\begin{array}{lc}\text { Anatomical Site } & \text { Percentage } \\ \text { 1.Whole Globe } & 17 \% \\ \text { 2.Cornea } & 18 \% \\ \text { 3.Lens } & 11 \% \\ \text { 4.Uvea } & 6 \% \\ \text { 5.Retina } & 12 \% \\ \text { 6.Optic Nerve } & 3 \% \\ \text { 7.Glaucoma } & 6 \% \\ \text { 8.Others } & 27 \% \\ \text { (Refractive Errors) } & \end{array}$

(Refractive Errors)

\begin{tabular}{|lcc|}
\hline & Sex Ratio Anatomical Causes \\
\hline & Male & Female \\
\hline Globe Anomalies & $11 \%$ & $\mathbf{6 \%}$ \\
\hline Cornea & $\mathbf{8 \%}$ & $\mathbf{1 0 \%}$ \\
\hline Lens & $\mathbf{7 \%}$ & $\mathbf{4 \%}$ \\
\hline Uvea & $\mathbf{4 \%}$ & $\mathbf{2 \%}$ \\
\hline Retin & $\mathbf{5 \%}$ & $\mathbf{7 \%}$ \\
\hline Optic Nerve & $1 \%$ & $\mathbf{2 \%}$ \\
\hline Glaucoma & $\mathbf{3 \%}$ & $\mathbf{3 \%}$ \\
\hline Refractive Error & $\mathbf{1 5 \%}$ & $\mathbf{1 2 \%}$ \\
\hline
\end{tabular}




\begin{tabular}{|lc|}
\hline Sex Distribution & \\
\hline Males & $54 \%$ \\
\hline Females & $46 \%$ \\
\hline Aetiological Causes Of Blindness & \\
\hline Hereditary/Genetic causes & $29 \%$ \\
\hline Intra uterine causes & $1 \%$ \\
\hline Childhood causes & $19 \%$ \\
\hline Indeterminate & $51 \%$ \\
\hline & \\
\hline
\end{tabular}

\section{Results Of Study On Refractive Errors}

- Hypermetropia is slightly is more common in childhood in the general population attending schools.

- However,in this study only children with best corrected visual acuity less than $6 / 60$ in the better eye

were included. The results obtained were as follows:

Male Female

Myopia

8

Hpermetropia

6

8

Astigmatism

1

4

0

Causes Of Blindness

Preventablecauses

Corneal scar

$19 \%$

Treatable Causes

Refractive Errors $\quad 27 \%$

Congenital cataract

$$
8 \%
$$

$6 \%$

Others

Globe anomalies $\quad 17 \%$

Retinal degeneration $\quad 10 \%$

Age distribution:

Age Group

$0-1$ month(Neonate)

1 month-1 year(Infant)

$0 \%$

Percentage

$1-3$ years(Toddler)

$1 \%$

$6 \%$

$2 \%$

3-5 years(Pre-school)

$93 \%$

5-15 years(School)

Prevalence Of Childhood Blindness

Total number of children attending the deparment 4694

$\mathrm{NO}$ of blind children were

123

Prevalence $=$ No of cases (old\&new) $* 100$

$P=123 / 4694 * 100=2.5 \%$

Total population

\section{Conclusion}

As More Than Half(63\%) Of Childhood Blindness Is Avoidable,Emphasis Should Be Given To Prevent Childhood Blindness Through Cost Effective Strategies.

- Coneal scar due to vitamin A deficiency being the most important preventable cause of childhood blindness, the most important long-term sustainable strategy for the control of Vitamin A deficiency is an improvement in the nutrition of infants and pre-school children and immunization against Measles.

- Uncorrected refractive errors are a common cause of visual impairment during childhood.More than $90 \%$ of cases of childhood blindness have been detected in the 5-15 year age group. This figure suggests the importance of regular screening of school children for refractive errors.

- Early provision of corrective spectacles will go a long way in reducing blindness in children.

- There is an urgent need to create awareness among general public and specially the school managements regarding the special needs of visually challenged children to enable them to realize their full potential and also make their schooling safe and enjoyable. 
- Genetic counselling to families prone to inheritable eye diseases like Retinitis pigmentosa may help to reduce other causes of blindness. Other public health measures like promotion of Rubellavaccination of all teenage girls could futher contribute to reduction of preventable blindness in children as approximately $25 \%$ of congenital cataract cases are due to Rubella syndrome.

- Congenital cataract forms $8 \%$ and congenital glaucoma forms $6 \%$ of the causes of blindness. Prompt identification of these correctable problems, good referral system and availability of tertiary eye care are important to tackle this problem. Good sugery and post surgical visual rehabilitation are crucial for a good outcome in these cases.

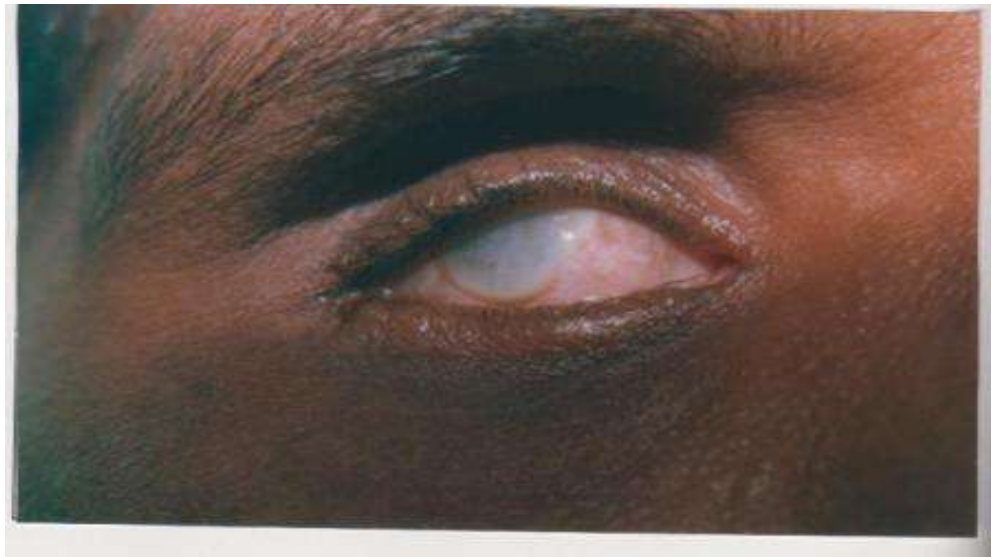

Sclero Cornea

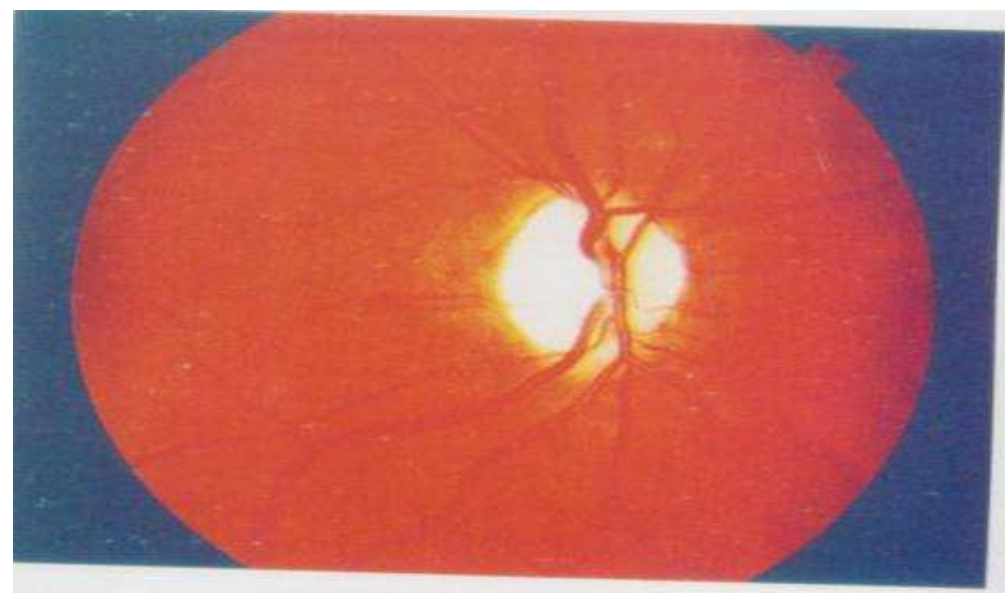

Primary Optic Atrophy

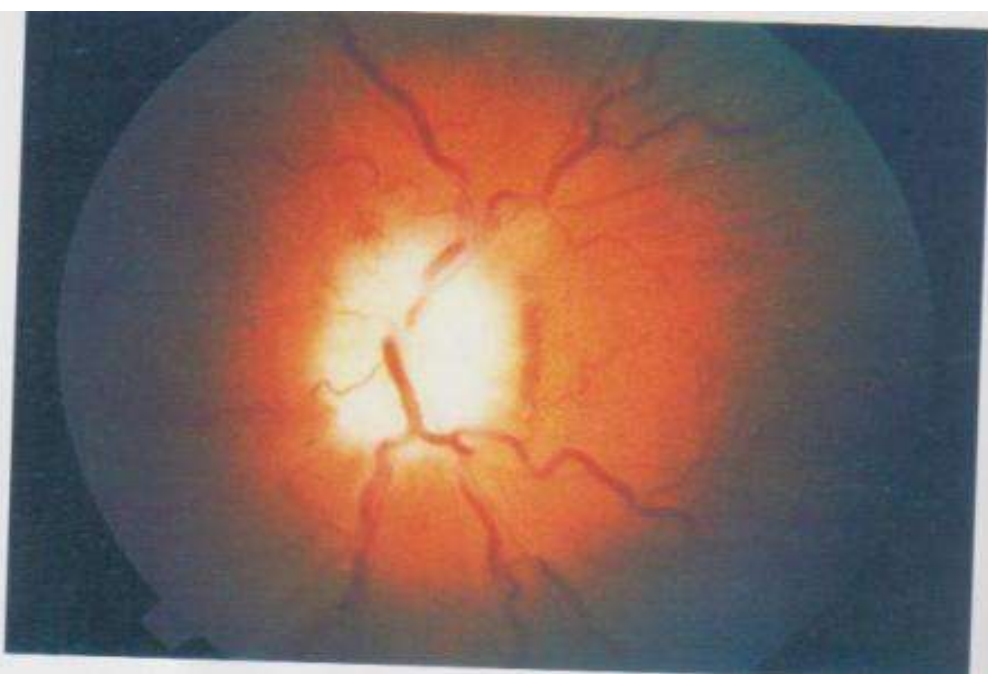

Secondery Optic Atrophy 


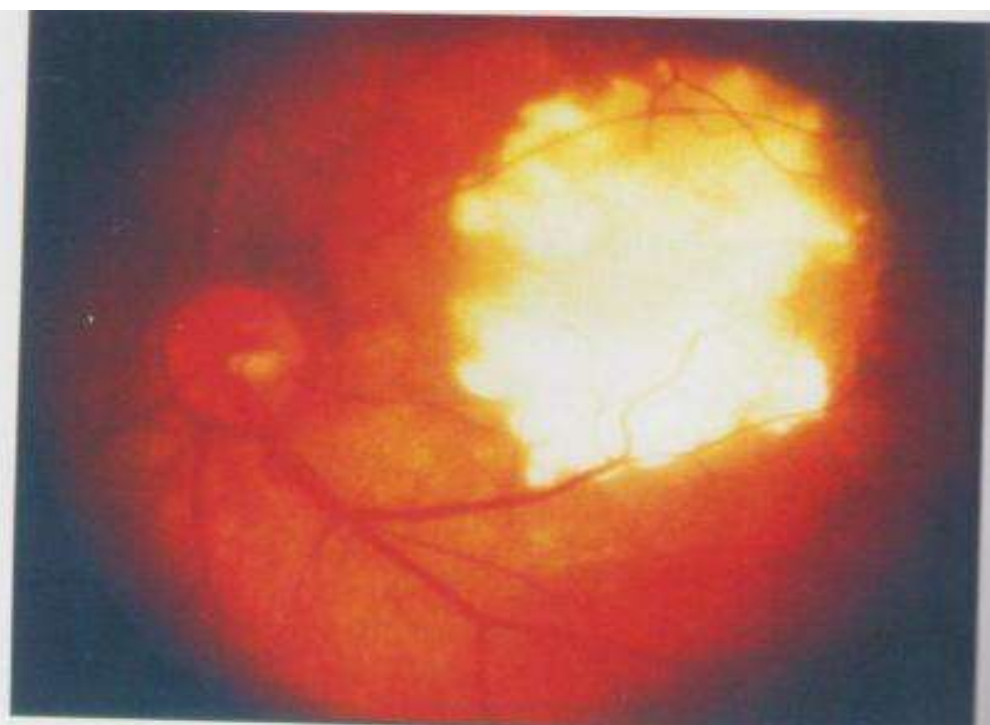

\section{Retinoblastoma}

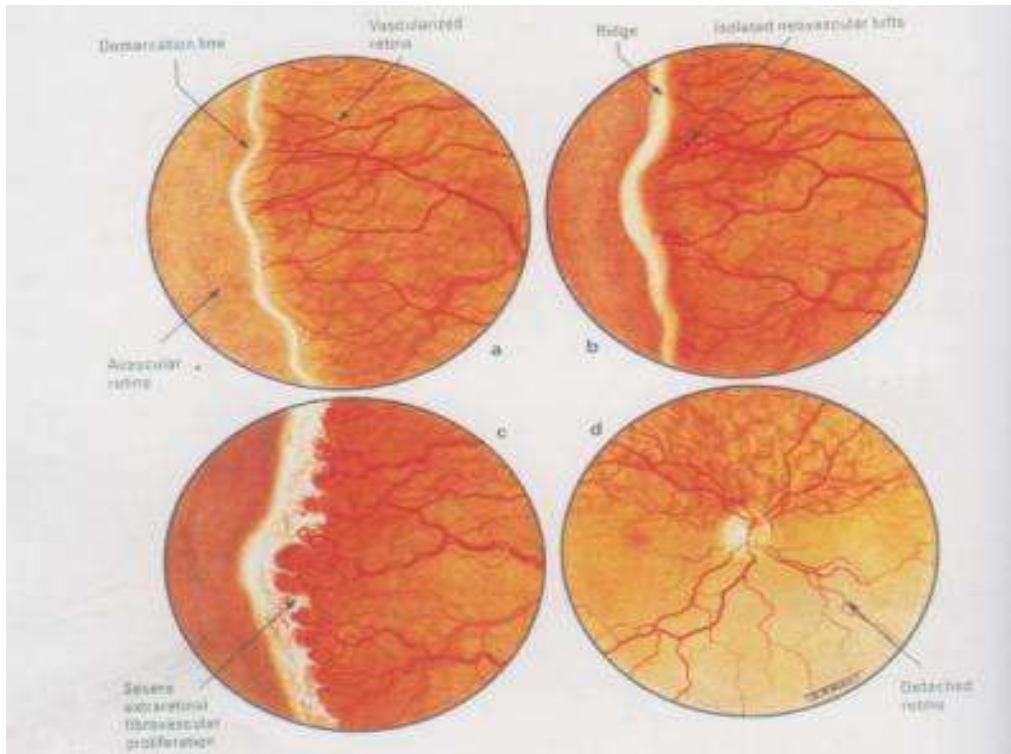

Progresson Of Retinophy Of Prematurity

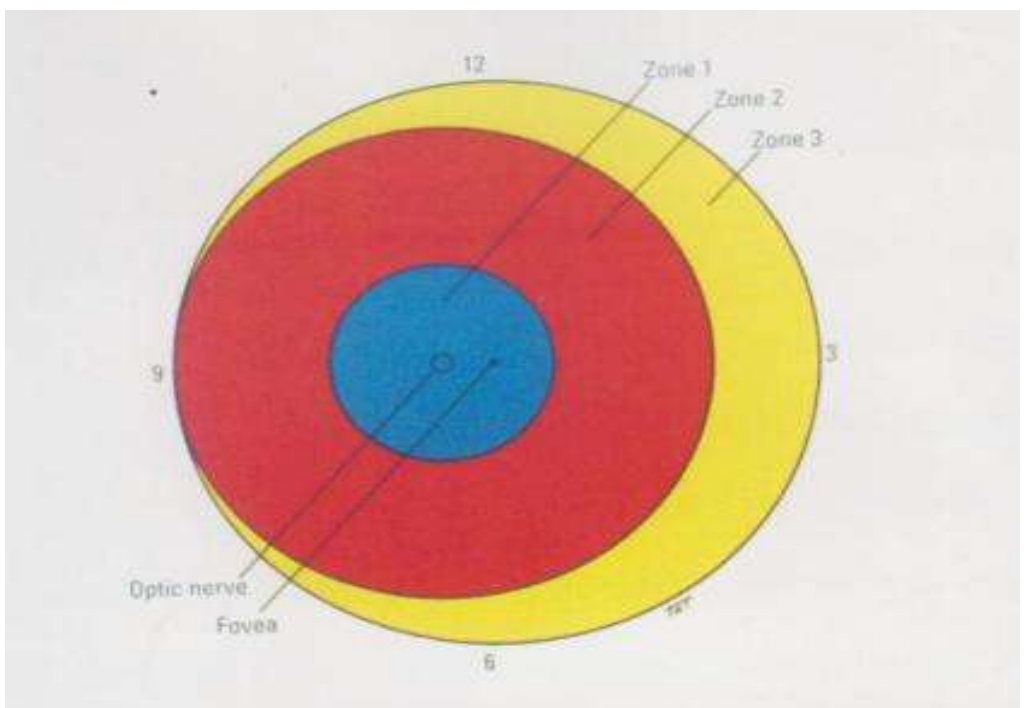

Grading Of Retinopathy Of Prematurity 


\section{Bibliography}

[1]. Duke Elder System of Ophthalmology Vol III Part 2 (Congenital Deformities)

[2]. Helveston, Ellis-Pediatric Ophthalmology practice

[3]. Myron Yanoff, Jay S Duker Ophthalmology- $2^{\text {nd }}$ Edition

[4]. Parsons's Diseases of the Eye $-19^{\text {th }}$ Edition

[5]. $\quad$ Stephen Ryan - Medical Retina Vol II -Andrew.P. Schachat

[6]. Modern Ophthalmology by LC Dutta $-2^{\text {nd }}$ Edition

[7]. Prevalence and causes of blindness in children in Andhra Pradesh-Dandona and Dandona(Br.J.O '03)

[8]. Planning to reduce childhood blindness in India-Lalit Dandona, C.E.Gilbert, G.N.Rao(I.J.O '98)

[9]. Visual impairment in school children in southern India-AK Bansal, Lalit Dandona(I.J.O. '97)

[10]. Childhood blindness in india and SriLanka-Allen Foster(IJO '96)

[11]. Causes and temporal trends of blindness and severe visual impairment in children in schools for blind in India- JSTityal, RTandon, CEGilbert, GVSMurthy, SKGupta \& RBVajpayee (Br.J.O ‘03). 